\title{
Planning a Patient-Centered Parkinson's Disease Support Program: Insights from Narrative Medicine
}

\author{
Nancy Gross ${ }^{1}$, Melissa Nicolas², Susan Neigher ${ }^{3}$, Shannon McPartland4, Melvyn Heyes ${ }^{4}$, \\ Sandra Wrigley ${ }^{4}$, Roger Kurlan ${ }^{*}$ \\ ${ }^{1}$ Humanities in Medicine Program, Overlook Medical Center, Atlantic Health System, Summit, NJ, USA \\ ${ }^{2}$ University of Nevada, Reno, NV, USA \\ ${ }^{3}$ Private Practice, Randolph, NJ, USA \\ ${ }^{4}$ Atlantic Neuroscience Institute, Overlook Medical Center, Atlantic Health System, Summit, NJ, USA

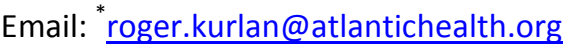

Received 15 September 2014; revised 17 October 2014; accepted 5 November 2014

Copyright (C) 2014 by authors and Scientific Research Publishing Inc.

This work is licensed under the Creative Commons Attribution International License (CC BY).

http://creativecommons.org/licenses/by/4.0/

(c) (i) Open Access

\section{Abstract}

Background: We desired relevant information from patients with Parkinson's disease (PD) and their caregivers for help in planning a long-term support program. Methods: We compared 3 approaches: 1) a standard needs assessment questionnaire, the Camberwell assessment of need in the elderly, 2) an open-ended listing of needs, and 3) participation in a narrative medicine program in which health care professionals were involved. Results: On the questionnaire, patients reported physical needs as the most important while their caregivers were more concerned about psychological needs. The open-ended listings revealed additional needs, particularly access to reliable information about PD and to opportunities to participate in clinical research. The narrative medicine process yielded a number of new insights and proposed solutions, particularly related to the heterogeneity of needs across individuals, the importance of providing hope, and the fact that caregivers expressed that their needs had been largely neglected. Participation in the narrative medicine sessions led to an increase in measured empathy by health care professionals, an improvement in measured depression among PD patients, but a worsening of measured depression among the caregivers. Conclusions: We have identified important needs and potential solutions to be considered in providing long-term support to patients with PD and their caregivers.

\section{Keywords}

Parkinson's Disease, Support, Narrative Medicine, Needs

\footnotetext{
${ }^{*}$ Corresponding author.
}

How to cite this paper: Gross, N., Nicolas, M., Neigher, S., McPartland, S., Heyes, M., Wrigley, S. and Kurlan, R. (2014) Planning a Patient-Centered Parkinson's Disease Support Program: Insights from Narrative Medicine. Advances in Parkinson's Disease, 3, 35-39. http://dx.doi.org/10.4236/apd.2014.34006 


\section{Introduction}

While existing treatments can substantially lessen the symptoms of Parkinson's disease (PD), patients with this neurodegenerative disease ultimately experience progressive disability. Over time, as the severity of illness changes, a wide spectrum of medical, psychological and social support resources become critical to patients and their families in order to lessen the burdens of illness [1] [2]. The provision of support resources and services usually occurs in an unorganized fashion with patients being referred to several different health care professionals and agencies with poor communications between them and an absence of integrated goals or processes. In order to overcome this problem, increase patient and caregiver satisfaction, improve quality of care, improve health outcomes and create care efficiencies, we set out to establish a formal, organized and integrated support program from diagnosis to death for patients with PD under care at our institution. Initial discussions and planning for the program occurred in a steering committee consisting of multidisciplinary health professionals. In order to ensure a "patient-centered" design for our program, the present study was carried out to obtain information about which support resources were considered to be of greatest need by PD patients themselves and their caregivers. In addition, we sought to determine which mechanism of information collection provided the best insights. For this, we compared a standard needs assessment questionnaire, an open-ended listing of anticipated needs, and participation in a narrative medicine program. The discipline of narrative medicine has developed as a model of medical practice that incorporates close reading of narratives (e.g., poems, short stories, essay, video clips), interpersonal discussions and reflective writings in order to generate empathy, reflection and trust between care providers and patients and their families [3]. Narrative medicine approaches have been applied to a variety of purposes, such as improving a therapeutic milieu, obtaining patient and family feedback on care services, and professional training [3]-[5].

\section{Methods}

Following appropriate institutionally approved informed consent, we enrolled 6 patients with PD, their 4 caregivers ( 1 patient was widowed and another's spouse was ill and could not participate) and 6 health care professionals. Each patient and caregiver completed an open-ended description of support resources anticipated to be needed over the course of the illness. Each separately participated in an interview by a social worker (MH) in order to complete the Camberwell Assessment of Need in the Elderly (CANE) [6]. This instrument includes 26 questions about areas of need for patients (e.g., housing, meals, falls) and 2 questions on areas of need for caregivers (information, psychological). Each patient and caregiver completed the self-report Geriatric Depression Scale (GDS) [7] and each health professional completed the self-report Jefferson Scale of Physician Empathy (JSPE) [8] just prior to and just after participating in the narrative medicine sessions. All 16 subjects jointly participated in 7 monthly narrative medicine sessions, each lasting about 90 minutes and led by a narrative medicine professional (NG) and a movement disorders neurologist (RK). Subjects were instructed to review assigned and provided readings before each session. Readings were selected for their relevance to potential challenges in dealing with a chronic, progressive illness like PD. The sessions consisted of interactive discussions about the meanings and implications of the material followed by self-reflective writing in response to a question relevant to the readings and potential needs of patients or caregivers. At the beginning of each subsequent session, themes extrapolated from the previously written narratives were brought forward and commented on. At the final session, each subject was again asked to write in an open-ended fashion about what support resources they anticipated in the course of PD.

Subject-produced writings from each narrative medicine session were reviewed for insights regarding anticipated support needs. They were also subjected to computerized lexical analysis using the Linguistic Inquiry and Word Count (LIWC) program developed by Pennebaker and colleagues [9]. We compared the self-generated description of anticipated needs provided by patients and caregivers before and after the narrative medicine program. We also compared patient and caregiver GDS scores and clinician JES scores before and after participating in the narrative medicine program. When relevant, we compared results for the 3 participant groups: patients, caregivers and clinicians.

\section{Results}

Six PD patients ( 2 men, 4 women, average age $=73$ years [range: 67 to 86], average duration of PD $=9$ years [range: 2 to 16 years], Hoehn and Yahr stages II [n = 3], III [n = 2], IV [n = 1]), their 4 available caregivers (2 
men, 2 women, average age $=71$ years [range: 67 to 78 years]) and 6 health professionals (neurologist, rehabilitation physician, 2 nurses, speech therapist, 2 internal medicine residents; age range 28 to 60) participated in the study.

On the CANE, PD patients reported physical mobility, psychological distress, physical health, eyesight/hearing issues and safety of self and others as the areas of greatest need. In contrast, caregivers rated psychological distress and potential for patient self-harm as greater needs than the physical problems the patients focused on.

In the initial open-ended descriptions of anticipated needs, obtained prior to the narrative medicine sessions, PD patient and caregiver groups listed needs that were similar to each other. There were several needs not conveyed in the CANE, particularly a need for easy access to accurate information regarding the diagnosis of PD, the symptoms of the illness, medication therapy, recent research findings, clinical research opportunities, and opportunities to be involved with the PD community. Subjects also reported the need for support programs for exercise, speech and psychological coping. Both the listings of anticipated needs and the CANE indicated needs for support services related to transportation, financial planning, future life planning, and activities of daily living, especially food preparation and housekeeping.

After the narrative medicine sessions, patient and caregiver groups again listed needs that were similar to each other. Compared to the initial listings, the post-sessions listings included more specific information about needs and included some specific solutions. For example, they requested a centralized website that could serve as an information aggregator, informational classes and support groups for patients recently diagnosed with PD and their caregivers, the availability of case managers to help them better understand available resources, mentoring of newly diagnosed patients by those with longer standing illness, creating patient "buying clubs" to reduce drug costs, and forming support groups around shared activities (e.g., knitting, music, photography, dance, volunteerism) and shared intellectual interests (e.g., books, politics, lobbying for PD research).

On the GDS, patients experienced a decline in depression scores, from a mean of 3.80 at baseline to 3.50 after the narrative sessions. Interestingly, caregivers showed an increase in measured depressive symptoms (mean score 1.33 at baseline and 9.00 after the sessions). On the JSPE, the health professionals demonstrated an increase in measured empathy (mean score of 120.67 before the sessions, 126.00 afterward). The number of subjects was too small to apply statistical tests of significance.

Surprisingly, lexical analyses of the written narratives revealed that caregivers expressed the most anger, anxiety, and negativity and they expressed many needs of their own, including help in dealing with their own fears and with obtaining assistance in caregiving. Caregivers felt neglected, seeing that most of the attention and discussions about care and support were directed at the person with PD. Additionally, the narratives identified the existence of substantial interpersonal strains between patients and their caregivers and other family members.

\section{Discussion}

The use of the CANE provided standard and expected information about anticipated needs. This is probably because the instrument has fixed domains of need that are assessed. There is no opportunity for subjects to report other needs. Interestingly, though, we found a difference between patients and caregivers regarding their need priorities. The fact that patients focused on physical needs while caregivers emphasized psychological needs is probably not surprising given information indicating that spousal caregivers of patients with PD reported greater burdens from mental than physical stresses [10] and that measured caregiver burden is closely associated with psychiatric features of the illness [11]. In addition, it has been reported that caregiver emotional distress is strongly dependent on the degree of depression in the PD patient [12].

The open-ended listing of anticipated needs yielded new information beyond that obtained by the CANE. In particular was an expressed need by patients and caregivers for information and education about PD. There was also again a focus on the need for support with psychological coping. It was clear that the open-ended listings of needs provided after the narrative medicine sessions were quite different, with both patients and caregivers expressing very specific and concrete suggestions for support resources. Many of these were excellent suggestions for incorporation into our support program. Undoubtedly, the narrative medicine program provided literary context for thought and opportunities for discussion that encouraged a deeper, richer and more concrete formulation of needs and support options.

The observed improvement in depression scores for our PD patients after the narrative program was anticipated and is consistent with the reported long-term improvement in emotional and physical health after expressive writing observed in a variety of illnesses [3] [5]. On the other hand, the worsening of depression among the 
caregivers was unexpected and may have been related to being encouraged to recognize and express feelings that may have been previously suppressed or seeing the decline of more advanced patients in the group which may have forced them out of denial or have threatened their feelings of optimism or hope.

Narrative medicine has been used successfully in training medical residents and mentoring physicians and other health care providers to better communicate and empathize with patients in order to improve the quality of patient care [3] [13]. Therefore, the measured increase in empathy among the health care professionals was consistent with prior observations. This appears to be an accompanying benefit of the narrative approach.

The narrative medicine process clearly yielded a large number of insights regarding the development of a support program that were not evident by the other methods utilized. Some of the key insights are summarized as follows. First, the group concluded that a population of PD patients cannot be viewed as a homogeneous entity since the illness's manifestations and the patient's responses are as unique as each individual who is faced with its challenges. Each patient and care partner (the term "care partner" was offered by patient and caregiver participants as a preferred alternative to "caregiver" or "caretaker") brings their own set of strengths and weaknesses in coping with PD. Pre-illness personality traits and relationship qualities appear to carry through after the diagnosis and must be considered in assessing support needs. Thus, because of this heterogeneity of people, there will be no support approach or set of resources that satisfies everyone's needs. What works for one person may not work for another, and a series of support options is needed from which patients and their care partners can choose. Second, patients differ in terms of when they are ready for information and action. The need to understand their illness is a clear responsibility of a patient once diagnosed, but some may need time to become ready. Being able to put the information into perspective is an important quality that may take time to develop. For some, denial is an impediment, for others it is a positive way to bide time until they are ready to learn more. Therefore, the best timing of support interventions may be very different from person to person. Health care professionals should be ready to provide the information the patient wants and is ready for-no more, no less. Third, the group concluded that the provision of optimum support begins with the diagnosing physician. It was apparent that when discussing the diagnosis and its implications, the physician should aim for the middle ground where truth and hope can reside together. There was general agreement that a critical, and unfortunately often missing, aspect at the time of diagnosis of PD is the need for the physician to instill hope. This is also needed throughout the course of PD. Patients explained that true hope arrives for a patient only when they recognize that there are real options and they have genuine choices. The best support program will provide such options. Hope can flourish only when the patient believes that what they do can make a difference, that their actions can bring a different future. To have hope is to have belief in one's ability to have some control over their circumstances; that one is no longer strictly at the mercy of the illness. Feelings of loss of control, that the disease controls you, contribute to loss of hope. It was also agreed that a good and supporting physician acts as a guide, providing choices, understanding and knowledge which give control. Recent scientific evidence that suggests engaging in regular physical exercise might improve the symptoms of PD and possibly favorably influence its course [14] was given as a good example of actions that might allow patients to regain some control over their illness. Participation in research is another potential mechanism that was discussed.

\section{Conclusion}

Overall, we found that the narrative medicine approach allowed healthcare professionals to engage in imperative discussions about healthcare with patients and their care partners, to deepen understanding of their needs in a patient-centered fashion and to better align support services with those needs. Although time consuming, narrative medicine methods allowed participants to contemplate their needs and to articulate their thoughts about those needs. In addition to providing a context for engagement and for support in an emotionally and intellectually challenging way, the narrative medicine approach yielded important insights that were not identified by other, briefer and more commonly used approaches such as questionnaires and assessment instruments. In particular, we learned about the important need for additional support services directed not only to patients with PD but also to their care partners and focused on their interpersonal relationships and stresses and their need for ongoing hope in dealing with the illness.

\section{Conflicts of Interest/Financial Disclosures}

None. 


\section{Roles}

All authors participated in the gathering and analysis of data. All participated in preparation and review of the manuscript.

\section{References}

[1] Kristjanson, L.J., Aoun, S.M. and Yates, P. (2006) Are Supportive Services Meeting the Needs of Australians with Neurodegenerative Conditions and Their Families? Journal of Palliative Care, 22, 151-157.

[2] Roland, K.P., Jenkins, M.E. and Johnson, A.M. (2010) An Exploration of the Burden Experienced by Spousal Caregivers of Individuals with Parkinson's Disease. Movement Disorders, 25, 189-193. http://dx.doi.org/10.1002/mds.22939

[3] Charon, R. (2001) Narrative Medicine. A Model for Empathy, Reflection, Profession, and Trust. JAMA, 286, 18971902. http://dx.doi.org/10.1001/jama.286.15.1897

[4] Sands, S.A., Stanley, P. and Charon, R. (2008) Pediatric Narrative Oncology: Interprofessional Training to Promote Empathy, Build Teams, and Prevent Burn out. Journal of Supportive Oncology, 6, 307-312.

[5] Benbow, S.M., Ong, Y.L., Black, S. and Garner, J. (2009) Narratives in a Users' and Carer's Group: Meanings and Impact. International Psychogeriatrics, 21, 33-39. http://dx.doi.org/10.1017/S1041610208007874

[6] Walters, K., Iliffe, S., Tai, S.S. and Orrell, M. (2000) Assessing Needs from Patient, Carer and Professional Perspectives: The Camberwell Assessment of Need for Elderly in Primary Care. Age Aging, 29, 505-510. http://dx.doi.org/10.1093/ageing/29.6.505

[7] Yesavage, J.A., Brink, T.L., Rose, T.L., et al. (1983) Development and Validation of a Geriatric Depression Screening Scale: A Preliminary Report. Journal of Psychiatric Research, 17, 37-49. http://dx.doi.org/10.1016/0022-3956(82)90033-4

[8] Hojat, M., Gonnella, J.S., Nasca, T.J., et al. (2002) The Jefferson Scale of Physician Empathy: Further Psychometric Data and Differences by Gender and Specialty at Item Level. Academic Medicine, 77, S58-S60. http://dx.doi.org/10.1097/00001888-200210001-00019

[9] Tausczik, Y.R. and Pennebaker, J.W. (2010) The Psychological Meaning of Words: LIWC and Computerized Text Analysis Methods. Journal of Language and Social Psychology, 29, 24-54. http://dx.doi.org/10.1177/0261927X09351676

[10] Roland, K.P., Jenkins, M.E. and Johnson, A.M. (2010) An Exploration of the Burden Experienced by Spousal Caregivers of Individuals with Parkinson's Disease. Movement Disorders, 25, 189-193. http://dx.doi.org/10.1002/mds.22939

[11] Schrag, A., Hovris, A., Morley, D., et al. (2006) Caregiver-Burden in Parkinson's Disease Is Closely Associated with Psychiatric Symptoms, Falls and Disability. Parkinsonism \& Related Disorders, 12, 35-41. http://dx.doi.org/10.1016/j.parkreldis.2005.06.011

[12] Thommessen, B., Aarsland, D., Braekus, A., et al. (2002) The Psychosocial Burden on Spouses of the Elderly with Stroke, Dementia and Parkinson's Disease. International Journal of Geriatric Psychiatry, 17, 78-84. http://dx.doi.org/10.1002/gps.524

[13] Alcauskas, M. and Charon, R. (2008) Right Brain: Reading, Writing and Reflecting. Making a Case for Narrative Medicine in Neurology. Archives of Neurology, 70, 891-894. http://dx.doi.org/10.1212/01.wnl.0000304945.48551.13

[14] Petzinger, G.M., Fisher, B.E., Van Leeuwen, J.-E., et al. (2010) Enhancing Neuroplasticity in the Basal Ganglia: The Role of Exercise in Parkinson's Disease. Movement Disorders, 25, S141-S145. http://dx.doi.org/10.1002/mds.22782 
Scientific Research Publishing (SCIRP) is one of the largest Open Access journal publishers. It is currently publishing more than 200 open access, online, peer-reviewed journals covering a wide range of academic disciplines. SCIRP serves the worldwide academic communities and contributes to the progress and application of science with its publication.

Other selected journals from SCIRP are listed as below. Submit your manuscript to us via either submit@scirp.org or Online Submission Portal.
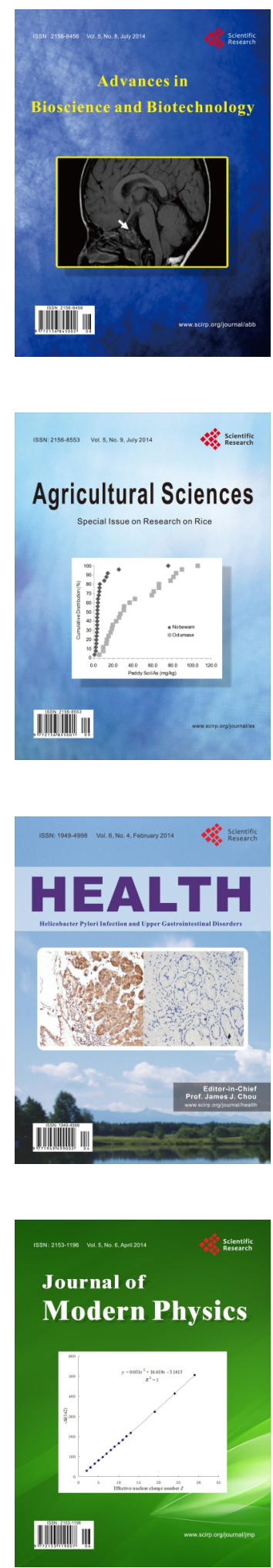
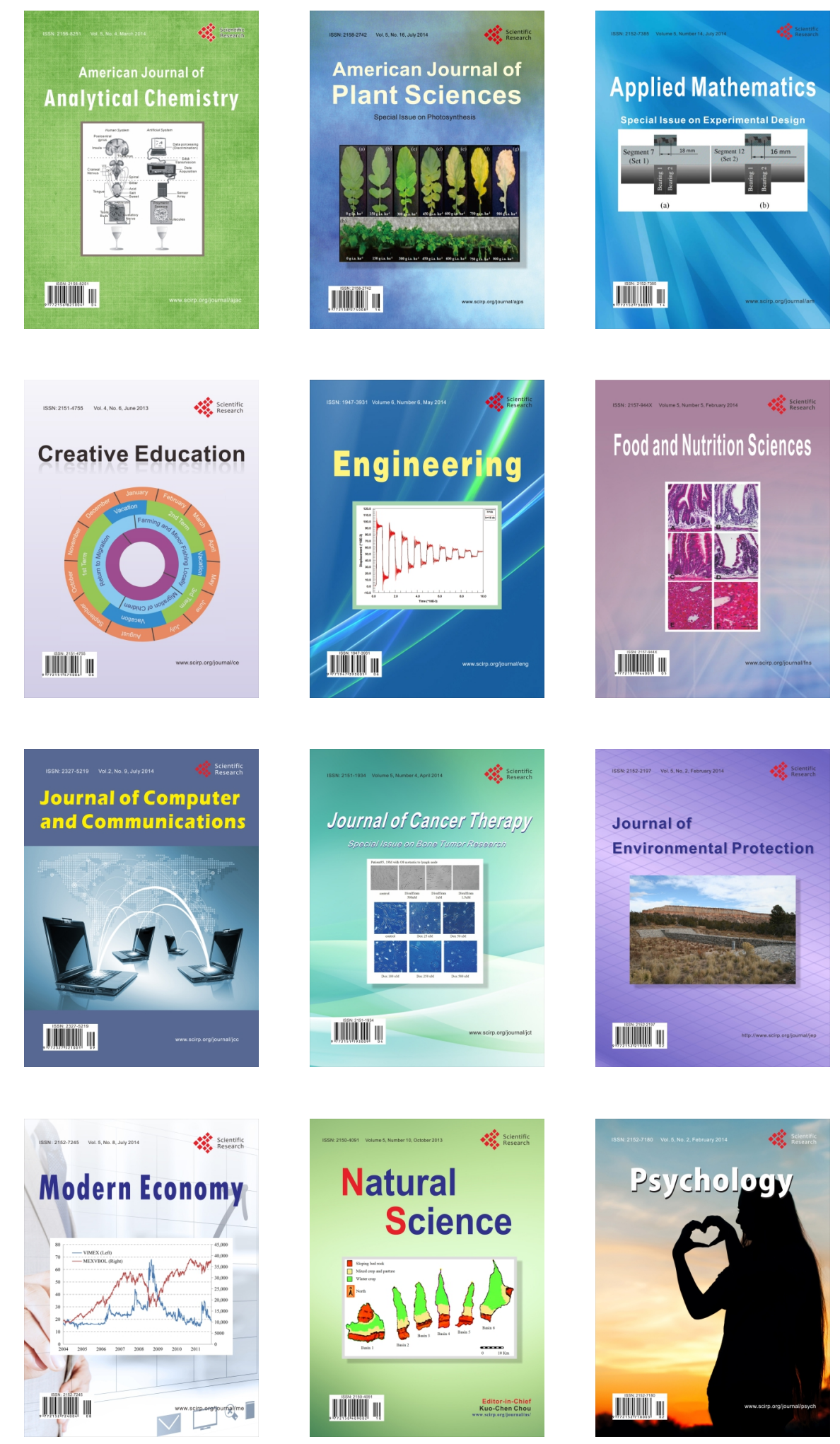